\title{
A STUDY ON BIOCHEMICAL PROFILES OF HYDATID CYST FLUIDS FROM RUMINANTS AND HUMANS IN PUNJAB, PAKISTAN
}

\author{
A. A. Latif ${ }^{1}$, M. Mansha ${ }^{2}$, A. Tanveer ${ }^{3}$ M. S. Rana ${ }^{4}$ and S. Fatima ${ }^{1}$ \\ ${ }^{1}$ Department of Zoology, Lahore College for Women University Lahore, Pakistan. ${ }^{2}$ Department of Zoology, \\ Division Science and technology, University of Education, Lahore. ${ }^{3}$ Department of Zoology, University of the \\ Punjab Lahore, Pakistan; ${ }^{4}$ Department of Medical Entomology and Vector control, Health Services Academy, \\ Government of the Pakistan, Islamabad. \\ Corresponding Author's email:asma5latif@yahoo.com
}

\begin{abstract}
ABSTARCT
Echinococcus granulosus, a cestode parasite dwells in small intestine of canids and has intermediate hosts such as livestock and humans. Its infection in intermediate hosts results in hydatidosis. The objective of the study was to determine and analyse the biochemical profile manifested by hydatid cyst fluid (HCF) of various ruminants and humans. The fluid was aspirated from fertile and sterile cysts of infected sheep, goat, camel, buffalo, humans and subsequently subjected to biochemical analysis by Randox and Roche kits. The results revealed that in fertile isolates maximum values $(\mathrm{mg} / \mathrm{dl})$ of glucose $(100.91 \pm 6.63)$, cholesterol $(201.21 \pm 1.26)$, triglyceride $(192.4 \pm 1.83)$, potassium (119.85 \pm 0.49$)$ were recorded in sheep; calcium (10.18 \pm 0.24$)$, chloride (107.51 \pm 0.37$)$, urea $(67.58 \pm 0.44)$ in cattle; protein $(\mathrm{g} / \mathrm{l})(111.3 \pm 5.32)$, copper (41.24 \pm 1.38$)$, urea (73.08 \pm 3.68$)$ in camel, Uric acid (13.01 \pm 0.36$)$, creatinine ( $0.20 \pm 0.01)$, magnesium $(9.2 \pm 0.24)$ and sodium (122.3 \pm 0.64$)$ in human. In sterile isolates highest values of protein (118.39 \pm 8.78$)$, magnesium (7.75 \pm 0.35$)$ were observed in sheep; calcium (10.2 \pm 0.26$)$, potassium (7.83 \pm 0.36$)$, sodium (197.23 \pm 0.73$)$ in cattle; calcium (7.91 \pm 0.23$)$, triglyceride $(155.01 \pm 8.76)$, creatinine $(0.03 \pm 0.01)$, sodium $(19.05 \pm 1.22)$ in buffalo; uric acid (10.69 \pm 0.25$)$, glucose (118.97 \pm 0.31$)$, urea $(372.93 \pm 8.92)$, cholesterol $(201.73 \pm 2.11)$, triglyceride (183.39 \pm 1.93$)$ in camel and creatinine $(0.10 \pm 0.01)$ in human. Hence, biochemical profiles from fertile and sterile isolates showed significant differences among ruminants and human isolates and these parameters can be employed as diagnostic approach for identification of infection.
\end{abstract}

Key words: Echinococcus granulosus, biochemical, humans, ruminants, fertile and sterile cysts.

https://doi.org/10.36899/JAPS.2020.6.0161

Published online August 03,2020

\section{INTRODUCTION}

Hydatidosis is a neglected zoonotic disease and global public health problem caused by Echinococcus granulosus (Taherkhani et al., 2000; Shafiq et al., 2005; Torgerson et al., 2006; Esatgil et al., 2007; Tavakoli et al., 2008; Shafiq et al., 2009). The annual infection rate is 1.2 million in the world (Craig et al., 2007). It is mainly endemic to Asia particularly in Pakistan \& India, South America, Middle East and Australia (Pednekar et al., 2009). The infection rates among dairy animals are aggravating day by day in certain provinces (KPK) of Pakistan: buffaloes $(15.88 \%)$ followed by cows (15.79\%), sheep (15.38\%), and goats (3.25\%) (Haleem et al., 2018).

Echinococcus granulosus is a tapeworm which causes a parasitic disease, echinococcosis/ hydatidosis that affects various livestock and humans. Various strains of echinococcus have been identified with differential potential to infect the intermediate hosts like sheep, dog, camel, pig, human, and horse. The modern phylogenetic systematics has recognized nine different species of Echinococcus (Nakao et al., 2013). The parasites are found attached to the mucosa of the small intestine in the canids (definitive hosts like dogs, wolves and foxes) where they develop into adult stage. In definitive hosts, the eggs are produced within 4-6 weeks of infection which latter on are passed out with faeces. The eggs after ingestion by the intermediate host reach the liver, lungs and other viscera through blood or lymph where cyst development begins (Farmer et al., 1990; Zhang et al., 2003; Siracusano et al., 2012 a, b). The eggs develop in to oncosphere larvae which remain alive for several years regardless of the host immune system. The larvae are characterized by long-term growth in the intermediate host (Zhang et al., 2003). The oncospheres penetrate the intestinal mucosa and reach the liver via the blood stream. A cyst develops in the infected organ after variable time period (Eckert et al., 2001). The hydatid cyst is unilocular, filled with hydatid fluid which might be fertile or sterile. Fertile cysts containing protoscoleces parasites are maintained in the host by developing a protective mechanism against the immunological and physiological reactions occurring in the host (Diaz et al., 2000). Hydatid fluid has a complex mixture of excretory 
and secretory products resulting from protoscoleces and the germinal layer which armed the parasite with antigenic properties (Siracusano et al., 2009). Parasite molecules lead to the chronic establishment of the infection and interfere with the functional activity of the host's immune cells (Hewitson et al., 2009).

Analysis of hydatid cysts have performed for electrolytes, enzymes, nucleic acids, proteins, nitrogenous waste products, carbohydrates and lipids (Zeghir-Bouteldja et al., 2017). Currently, chromatographic method for enrichment of Antigen 5 and exosomal signatures derived from extracellular vesicles confined in cyst and are being employed as analytical tools for hydatid cyst fluid (Siles-Lucas, 2017). Determination of the chemical and biochemical parameters in hydatid cyst fluids of infected sheep and cattle may help to identify the source of human infection. Statistically significant differences in the fluid of hydatid cyst collected from sheep, goat, camel, cattle and human for comparative study on the biochemical parameters in Iran has been reported (Radfar et al., 2004). Quantitative deviations in the levels of glucose, calcium and creatinine in the cystic fluids of camels, sheep, goat, cattle and humans were detected.

Keeping in view the escalating prevalence of hydatidosis, unawareness on the part of farmers and lack of appropriate approaches for its diagnosis, it is crucial to have preliminary information on biochemical analysis of both fertile and sterile hydatid cyst fluids from different species of animals and human beings by using various biochemical kits. Data obtained from comparative study of various biochemical parameters may indicate some common values for precise finding of hydatidosis in ruminants and humans.

\section{MATERIALS AND METHODS}

The present study was approved by ethical committee of primary author's university. Cysts were obtained from various animals such as cow, sheep, camel, and goat slaughtered in different abattoirs of Punjab. A total of 39,738 slaughtered animals were examined for hydatid cysts during postmortem inspection including 5300 buffaloes, 15,857 sheep, 15,001 goats, 2990 cattle and 590 camels. The hydatid cysts were obtained from liver and lungs of host animals. Each cyst was washed with distilled water and hydatid cyst fluid (HCF) was aspirated with sterile syringe with hypodermic needle No.18G. Hydatid cyst fluids were also collected from humans who were operated for hydatidosis in different hospitals of Punjab. All fluid samples were centrifuged at $15000 \mathrm{rpm}$ at $4^{\circ} \mathrm{C}$ for 30 minutes and supernatants were analysed for various biochemical parameters (Radfar et al., 2004). Ten samples were selected from each animal species isolate and 10 from human isolates (fertile and sterile $\mathrm{HCF}$ ). The biochemical parameters which are considered indicative of most of the diseases were analysed in the present study.

Estimation of urea $(\mathrm{mg} / \mathrm{dl})$, cholesterol $(\mathrm{mg} / \mathrm{dl})$, triglyceride $(\mathrm{mg} / \mathrm{dl})$, calcium $(\mathrm{mg} / \mathrm{dl})$, uric acid $(\mathrm{mg} / \mathrm{dl})$, glucose $(\mathrm{mg} / \mathrm{dl})$, total protein $(\mathrm{g} / \mathrm{l})$ and copper $(\mathrm{mmol} / \mathrm{l})$ were determined by using the RANDOX Kit according to the manufacturer's instructions. Estimation of magnesium $(\mathrm{mg} / \mathrm{dl})$ and creatinine $(\mathrm{mg} / \mathrm{dl})$ (Jaffe' method) were determined by using the Roche Kit according to the manufacturer's instructions. Roche automate 912 analyser was used to calculate the concentration of each sample. Fluid samples were evaluated for potassium $(\mathrm{mmol} / \mathrm{l})$, sodium $(\mathrm{mmol} / \mathrm{l})$ and chloride (mmol/l) electrolytes in Easy Lyte plus $\mathrm{Na} / \mathrm{K} / \mathrm{Cl}$. (MEDICA). Sample size was kept at $100 \mu \mathrm{l}$ and analysed for 60 seconds at $15-32^{\circ} \mathrm{C}$ and $85 \%$ humidity. Statistical analysis was done by Multivariate analysis (MNOVA) using SPSS 13.0.

\section{RESULTS}

Calcium (mg/dl) level was higher in fertile $(10.18 \pm 0.24)$ and sterile $(10.2 \pm 0.26)$ isolates of cattle and lower in fertile $(7.56 \pm 0.10)$ and sterile $(7.91 \pm 0.23)$ isolates of buffalo. Cholesterol $(\mathrm{mg} / \mathrm{dl})$ level was higher in fertile isolates of sheep $(201.21 \pm 1.26)$ and lower in camel $(103.23 \pm 0.75)$, while higher in sterile isolates of camel $(201.73 \pm 2.11)$, and lower in cattle $(148.05 \pm 6.55)$. Experimental study revealed, total protein (g/l) was higher in fertile isolates of camel $(111.3 \pm 5.32)$ and less in buffalo $(90.92 \pm 0.65)$, while maximum in sterile isolates of sheep (118.39 \pm 8.78$)$ and lower in camel $(5.04 \pm 0.65)$. Observed values showed that triglycerides $(\mathrm{mg} / \mathrm{dl})$ was higher in fertile isolates of sheep $(192.41 \pm 1.83)$ and less in camel (105.50 \pm 3.29$)$, while maximum in sterile isolates of camel $(183.39 \pm 1.93)$ and lower in buffalo $(155.01 \pm 8.76)$. Level of magnesium $(\mathrm{mg} / \mathrm{dl})$ was higher in fertile isolates of human $(9.20 \pm 0.24)$ and less in camel $(0.30 \pm 0.02)$, while maximum in sterile isolates of sheep $(7.76 \pm 0.35)$ and lower in buffalo $(0.08 \pm 0.01)$. Estimated value of potassium ( $\mathrm{mmol} / \mathrm{l})$ was higher in fertile isolates of sheep (119.85 \pm ) and less in buffalo (5.21 \pm 0.51$)$, while maximum in sterile isolates of cattle $(7.83 \pm 0.36)$ and lower in buffalo $(1.40 \pm 0.05)$. Uric acid $(\mathrm{mg} / \mathrm{dl})$ level in fertile groups was more in human $(13.01 \pm 0.0 .36)$ and less in camel $(9.45 \pm 0.15)$, while in sterile groups the value was higher in camel $(10.69 \pm 0.25)$ and lower in goat $(9.56 \pm 0.13)$. Copper $(\mathrm{mmol} / \mathrm{l})$ level was higher in fertile isolates of camel $(41.24 \pm 1.38)$ and less in buffalo $(21.17 \pm 1.51)$, while maximum in sterile isolates of goat $(37.46 \pm 1.42)$ and lower in camel $(15.47 \pm 0.92)$. Glucose $(\mathrm{mg} / \mathrm{dl})$ level was maximum in fertile isolates of sheep $(100.91 \pm 6.63)$ and less in buffalo $(63.92 \pm 0.80)$, while in sterile isolates was higher in camel $(118.97 \pm 0.31)$ and lower in cattle $(60.19 \pm 0.45)$. Creatinine $(\mathrm{mg} / \mathrm{dl})$ was higher in fertile isolates of human $(0.20 \pm 0.01)$ and less in 
buffalo $(0.04 \pm 0.01)$, while maximum in sterile isolates of human $(0.10 \pm 0.01)$ and lower in buffalo $(0.03 \pm 0.01)$. Urea $(\mathrm{mg} / \mathrm{dl})$ level was higher in fertile groups of camel
(73.08 \pm 3.68$)$ and less in sheep (47.34 \pm 0.79$)$, while in sterile groups values were higher in camel $(372.9 \pm 8.92)$ and lower in human $(43.72 \pm 0.29)$.

DSterile $\square$ Fertile

(A)

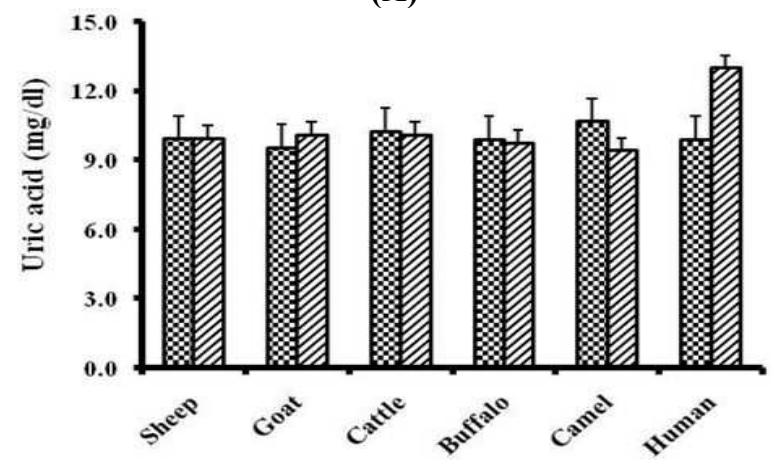

(C)

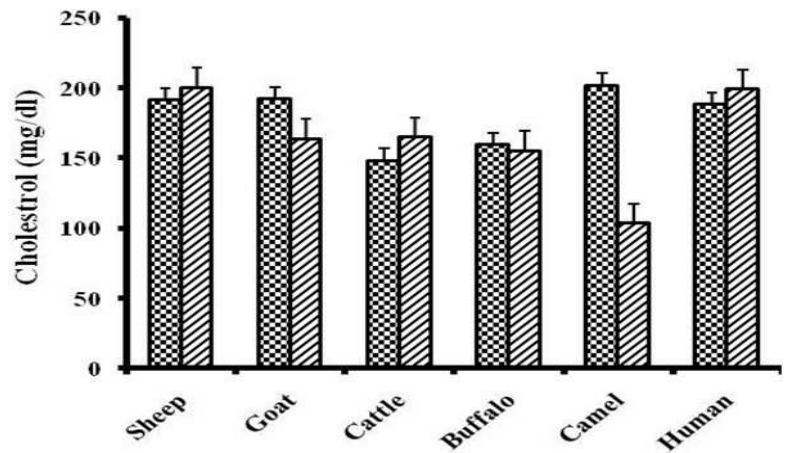

(E)

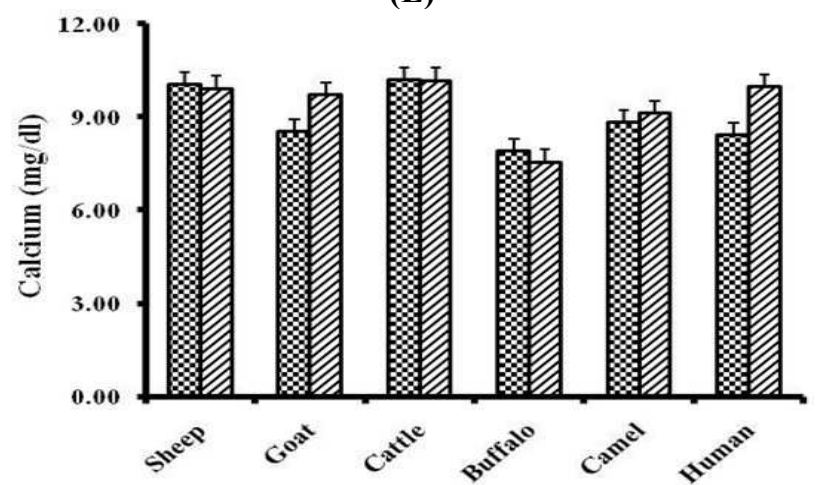

(G)

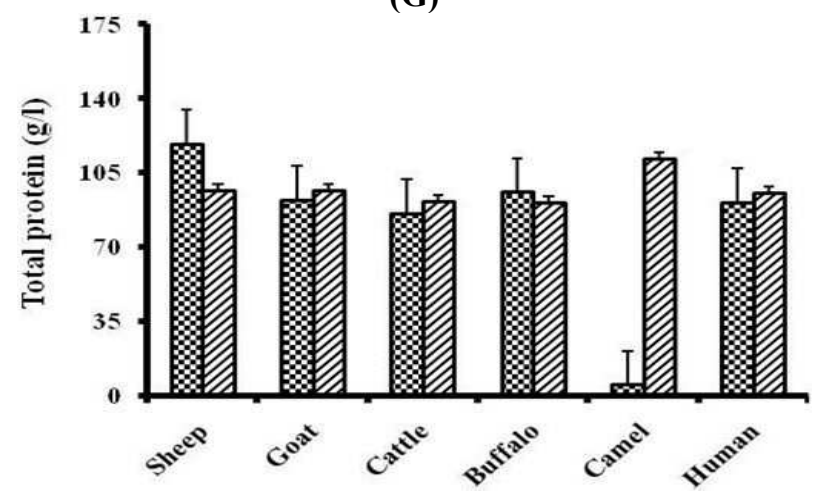

(B)

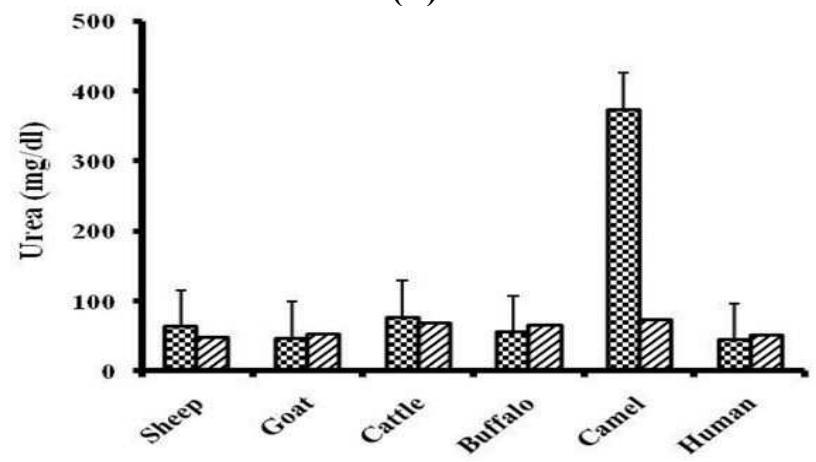

(D)

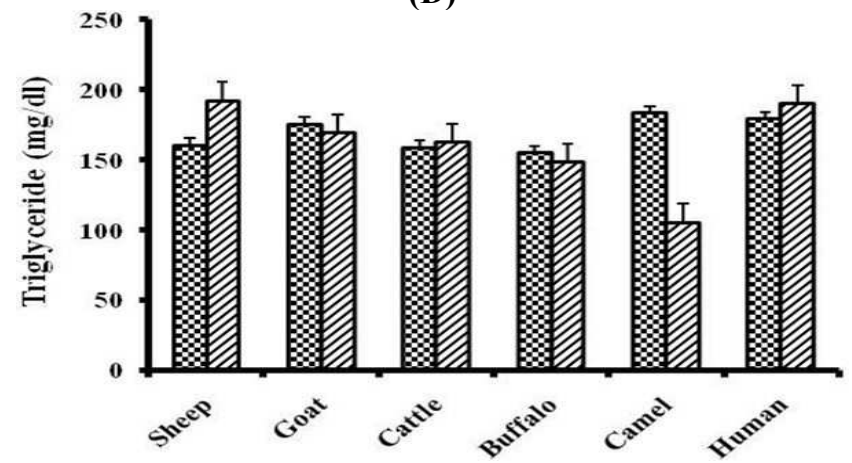

(F)

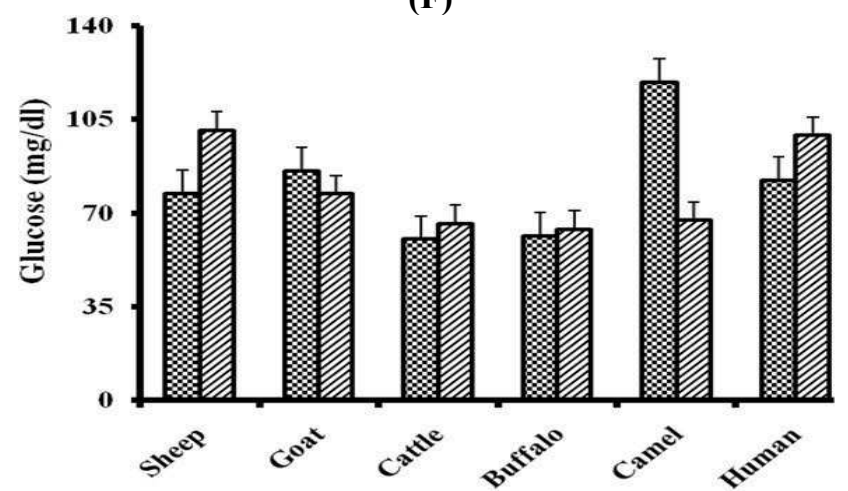

(H)

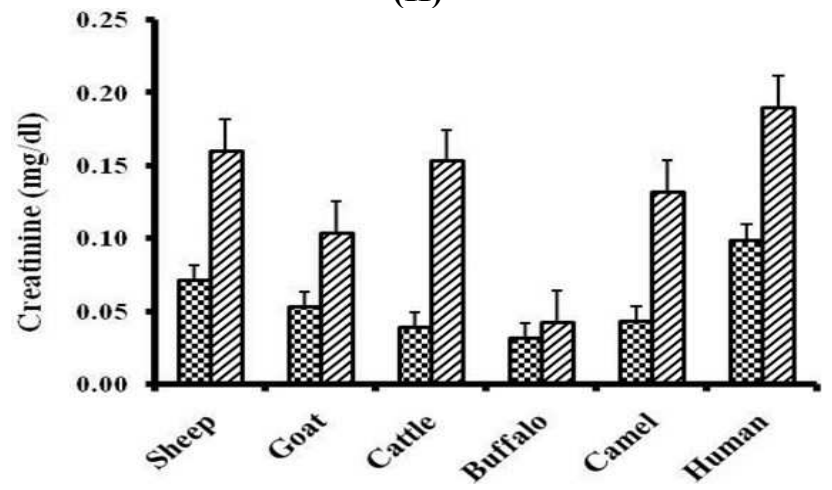


(I)

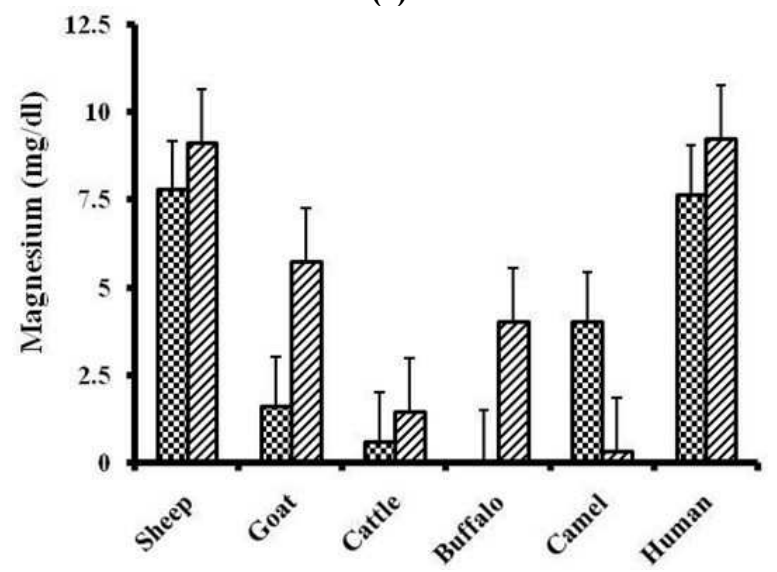

(K)
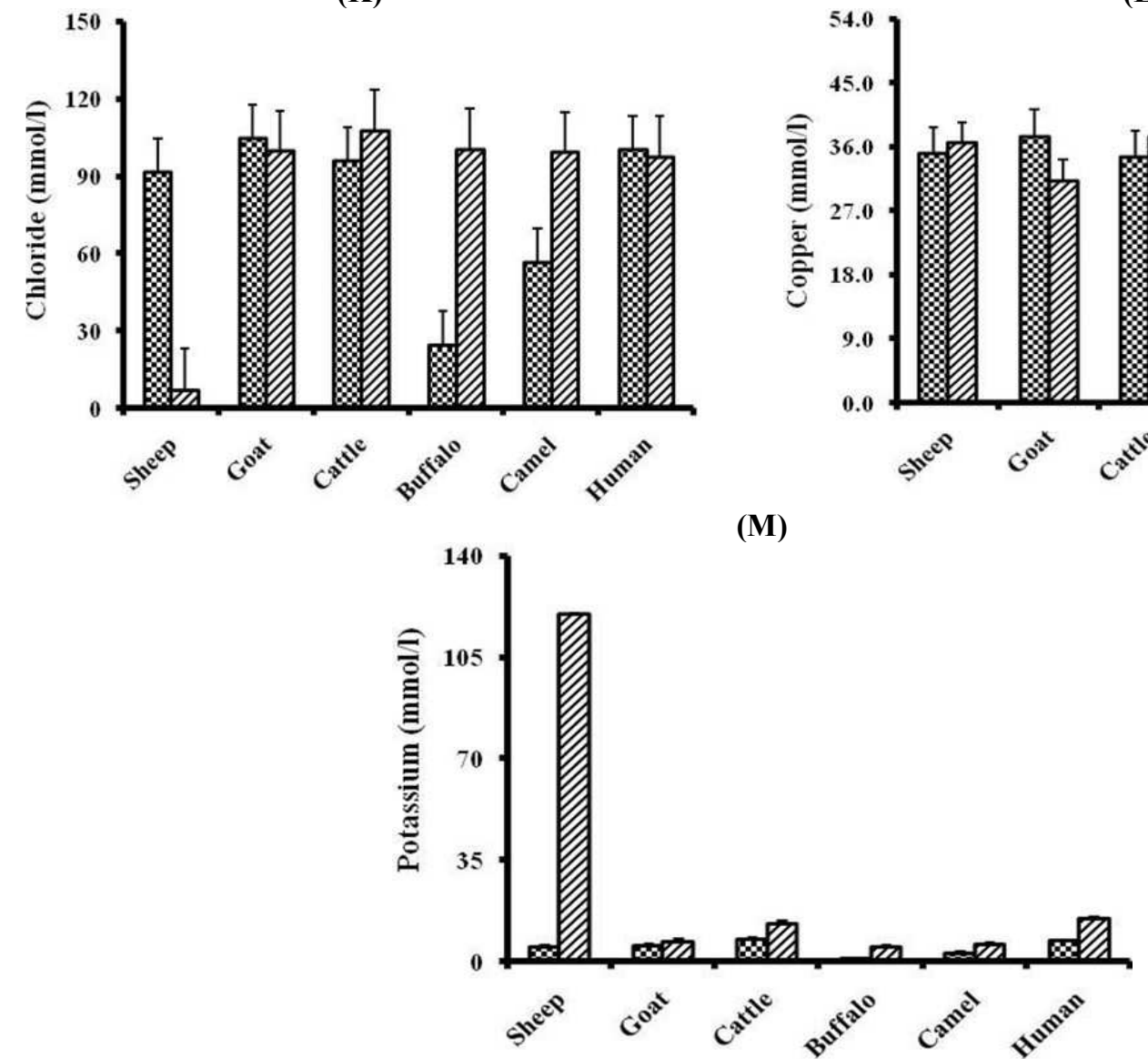

(M)
(J)

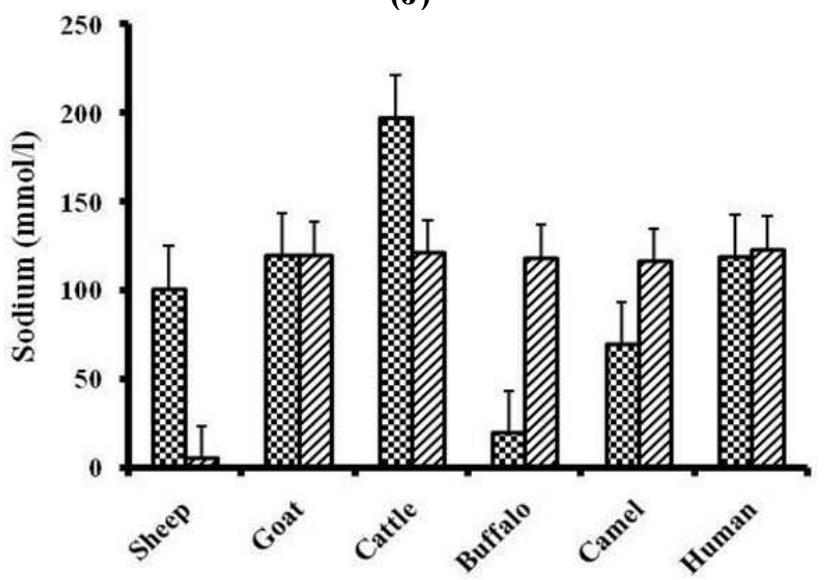

(L)

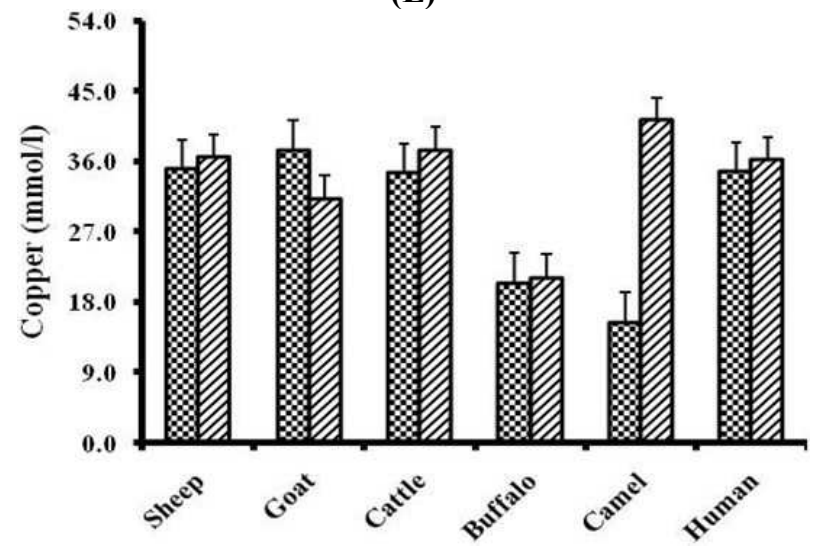

Fig. 1: Bar graph shows variation in biochemical profiles (mean $\pm \mathrm{SE}$ ) of fertile and sterile hydatid cyst fluids from various animals and human isolates

(A) Uric Acid (mg/dl); (B) Urea (mg/dl); (C) Cholesterol (mg/dl); (D)Triglyceride (mg/dl); (E) Calcium (mg/dl); (F) Glucose (mg/dl); (G) Total Protein (g/l); (H) Creatinine (mg/dl); (I) Magnesium (mg/dl); (J) Sodium (mmol/l); (K) Chloride (mmol/l); (L) Copper (mmol/l); (M) Potassium (mmol/1).

Chloride (mmol/l) contents were higher in fertile isolates of cattle (107.51 \pm 0.37$)$ and less in sheep (7.33 \pm 0.43$)$, while maximum in sterile isolates of goat $(104.48 \pm 0.51)$ and lower in buffalo (24.51 \pm 0.86$)$. Sodium (mmol/l) level were found higher in fertile isolates of human
(122.30 \pm 0.64$)$ and less in sheep (4.52 \pm 0.30$)$, while maximum in sterile isolates of cattle $(197.23 \pm 0.73)$ and lower in buffalo (19.05 \pm 1.22$)$ (Fig. 1). All values were significantly different $(p<0.05)$. 


\section{DISCUSSION}

Hydatidosis is a zoonotic disease affecting the dairy animals and humans on a large scale globally. A limited data regarding prevalence of hydatidosis is available from Sindh, Punjab and Khyber Pakhtunkhwa in Pakistan (Nadeem et al., 2006). The reported incidence rate of hydatidosis in various region of Pakistan from 1989 to 2015 was between 7.19 and $24.40 \%$ in buffaloes (Latif et al., 2010), 2.44 and 35\% in cattle (Latif et al., 2010; Ali et al., 2015) and 2.44 and $6.61 \%$ in goats (Latif et al., 2010; Iqbal et al., 2012).

The biochemical profiles from fertile and sterile isolates showed significant differences among all animal species and human isolates. The principal strain which causes infection in human is sheep strain (Thompson et al., 1995). Similar to our findings of potassium (mmol/l) values for sheep (sterile), camel (fertile) and goat (fertile) were reported by other authors (Thompson et al., 1995; Izadi and Ajami, 2006). Our results of sodium ( $\mathrm{mmol} / \mathrm{l})$ values for goat (sterile), human (fertile) and cattle (fertile) were comparable with the results reported by Izadi and Ajami (2006). Glucose, cholesterol, triglyceride and urea values found in present investigations were lower and creatinine were higher in cattle, sheep, goat, camel and human isolates as compared to the results of Izadi and Ajami (2006) and Juyi, (2013). Values of calcium for sheep (sterile), camel (fertile) and cattle (fertile, sterile) found in our results were nearly similar to the other reports. The higher values of sodium maintain that these elements enter the cyst to promote the growth of the parasites (Izadi and Ajami, 2006; Juyi , 2013).

In sheep (fertile) isolates, our results for $\mathrm{Ca}, \mathrm{Mg}$, $\mathrm{Na}, \mathrm{K}$ were different as compared to the Rahdar et al. (2008). Ca ions maintain the $\mathrm{pH}$ of the cyst and hence resist the development of acidity in it. Moreover, $\mathrm{Ca}$ and $\mathrm{Mg}$ ions are found in the calcareous bodies of the cyst (Frayha, et al., 1980). Total protein (g/l), copper (mmol/l), triglyceride levels for fertile and sterile isolates showed significant difference among human and animal species $p<0.05$, our values were different from those reported by Radfar and Iranyar (2004) and Izadi and Ajami (2006). Copper levels for fertile and sterile groups of sheep were lower than the values reported by Kojouri and Moshtaghi (2008). The levels reported by Rashid et al. (2013) for glucose, triglycerides, calcium varied from our work but sodium, potassium, chloride were nearly similar in all sterile samples of sheep and cattle. Buffalo species is endemic to India and Pakistan, so detailed report on this study could not be found from the literature available. Present analysis showed fertile and sterile isolates of buffalo revealed significant differences in urea, triglyceride, calcium, cholesterol, uric acid, potassium, magnesium, copper and insignificant difference in the values of chloride, creatinine, sodium, glucose and total protein.
Conclusion: Present study revealed significant variation of biochemical parameters in different hydatid cyst fluids of various intermediate hosts (animals and human) isolates. Variation in composition of hydatid cyst fluids in different species of animals and human may be due to multiple strains of E. granulosus in Punjab, Pakistan. This analysis will be further useful for immunological studies, diagnostic tests and may be helpful to find out various strains of E. granulosus in Punjab by using PCR technique.

\section{REFERENCES}

Ali, I., M.K. Panni, A. Iqbal, I.Muneer, S. Ahmad, and A. Ali (2015). Molecular characterization of echinococcus species in Khyber Pakhtunkhwa, Pakistan. Acta. Sci. Vet. 43: 1277- 81.

Craig, P.S., C.M. Budke, P.M. Schantz, L. Tiaoyin, Q. Jiamin, Y. Yurong (2007). Human echinococcosis: a neglected disease. Trop. Med. Health. 35:283-92.

Diaz, A., S. Ibarguren, M.B. Breijo, A.C. Willis, and R.B. Sim (2000). Host-derived annexin II at the hostparasite interface of the Echinococcus granulosus hydatid cyst. Mol. Biochem. Parasitol. 110: 171-176.

Eckert, T., M.A. Gemmell, F.X. Meslin, and Z.S. Pawlowski (2001). Echinococcosis in animal clinical aspects, diagnosis and treatment in: WHO/OIE manual on echinococcosis in human and animal Pris (France). 21 p.

Esatgil, U.M., and E. Tuzer (2007). Prevalence of hydatidosis in slaughtered animals. Türkiye. Parazitol. Derg. 31(1): 41-45.

Farmer, P.M., S., Chatterley, and N. Spier (1990). Echinococcal cyst of the liver, diagnosis and surgical management. Ann. Clin. Lab Sci. 20: 385-390.

Frayha, G.J., and Haddad (1980). Comparative chemical composition of protocolices and hydatid cyst fluids of Echinococous granulosus. Int. J. Parasitol.10: 359-364.

Hewitson, J.P., J.R. Grainger, and R.M. Maizels (2009). Helminth immunoregulation: the role of parasite secreted proteins in modulating host immunity. Mol. Biochem. Parasitol. 167: 1-11.

Iqbal, H. J., A. Maqbool, M. Lateef, M.A. Khan, A. Riaz, A. Mahmood (2012). Studies on hydatidosis in sheep and goats at Lahore, Pakistan. J Anim Plant Sci. 22:894-7.

Izadi, J., and A. Ajami (2006). Biochemical profiles of hydatid cyst fluids of Echinococcus granulosus of human and animal origin (sheep, goat, cattle and camel). J. Anim. Vet. Adv. 5(7): 574-577. 
Juyi, L., J. Yan, W. Xiufang, Z. Zhaoqing, L. Junliang, Z. Mingxing, and Z. Wei (2013). Analysis of the chemical components of hydatid fluid from Echinococcus granulosis. Rev. Soc. Bras. Med. Trop. 46(5):605-610.

Kojouri, G.A., and H.A. Hoshtaghi (2008). A comparative study on Copper, Zinc, Cobalt and Iron concentration in hydatid cyst (Fertile and Infertile) Fluid, Liver and Sheep Serum. Res. J. Parasitol. 3(2): 67-70.

Latif, A. A., A.Tanveer, A. Maqbool, N. Siddiqi, M. Kyaw-Tanner, and R. J. Traub (2010). Morphological and molecular characterisation of Echinococcus granulosus in livestock and humans in Punjab, Pakistan. Vet. Parasitol, 170(1-2), 44-49.

Nadeem, N. H., Khan, S., Fatimi, M.N., Ahmad (2006) Giant multiple intra-abdominal hydatid cysts. J. Ayub. Med. Coll. Abbottabad. 18(4):71-3.

Nakao, M., A. Lavikainen, T. Yanagida, and A. Ito, (2013). Phylogenetic systematics of the genus Echinococcus (Cestoda: Taeniidae). Int. J. Parasitol. 43(12-13),1017-1029.

Pednekar, P.R., M.L. Gatne, R.C. Thompson (2009). Molecular and morphological characterisation of Echinococcus from food-producing animals in India. Vet. Parasitol. 165: 58-65.

Radfar, M.H. and N. Iranyar (2004). Biochemical profiles of hydatid cyst fluids of Echinococcus granulosus of human and animal origin in Iran. Vet. Arhiv. 74(6): 435-442.

Rahdar, M., S. Maraghi, A. Rafei, and M. Razijalali (2008). Comparison of some electrolytes in hydatid cyst fluid and serum of liver hydatidosis of sheep. Jundishapur. J. Microbiol. 1(1): 1014.Refik, M., N. Mehmet, B. Durmaz, and M., Eğri (2002). Determination of some biochemical parameters in hydatid cyst fluids. Erciyes. Med. J. 24(1): 10-13.

Rashid, A., M. M. Darzi, M.S. Mir, S. A. Kamil, L.M. Dar, M. Ambreen, S. Abdullah (2013). Comparative biochemical analysis of hydatid fluid from ovine lungs and livers. Int. J. Livestock Res. 3(2): 108-111.

Shafiq, M., A. Tanveer, and M. Athar (2005). Epidemiology and economical aspects of hydatidosis/echinococcosis in different animals and man. Ph.D. Dissertation. Deptt. of Zool. Univ. Punjab, Lahore.

Shafiq, M., T. Akhter, M.A. Khan, H.T. Ammara, and T.J. Gill (2009). Present study of human hydatidosis in Punjab, Pakistan. Pakistan J. Sci. 60: 35-41.
Siles-Lucas, M., C. Sánchez-Ovejero, M. GonzálezSánchez, E. González, J.M. Falcón-Pérez, B. Boufana, F. Fratini, A. Casulli, and R. ManzanoRomán (2017). Isolation and characterization of exosomes derived from fertile sheep hydatid cysts. Vet. Parasitol. 15 (236):22-33.

Siracusano, A., A. Teggi and E. Ortona (2009). Human cystic echinococcosis: old problems and new perspectives. Interdiscip. Perspect. Infect. Dis. Article ID 474368. doi:10.1155/2009/474368.

Siracusano, A., F. Delunardo, A. Teggi, and E. Ortona (2012a). Host-parasite relationship in cystic Echinococcosis: an evolving story. Clin. Dev. Immunol. http://dx.doi.org/10.1155/2012/639362.

Siracusanoa, A., F. Delunardo, A. Teggi, and E. Ortona (2012b). Cystic echinococcosis: aspects of immune response, immunopathogenesis and immune evasion from the human host. Endocr. Metab. Immune. Disord. Drug Targets. 12:1623.

Haleem, S., N. Sadaf, S. Naveeda, A.Q., Riaz Ullah, M., Mansour, S.A. Ali and A.S., Abdelaaty (2018). Incidence, risk factors, and epidemiology of Cystic Echinococcosis: A complex socioecological emerging infectious disease in Khyber Pakhtunkhwa, Province of Pakistan. Hindawi. BioMed. Res. Int. Article ID 5042430.

Taherkhani, H., and M.T. Rogan (2000). General characterization of laminated layer of Echinococcus granulosus. Iranian. J. Med. Sci. 25: 95-104.

Tavakoli, H., J.N. Jonaidi, M. Izadi, and M. Parsa (2008). Epidemiological investigation of hydatidosis infections in Iran. 18th European Congress of Clin. Microbiol. Infect. Dis. Barcelona, Spain. 19-22.

Thompson, R.C.A., and A.J. Lymbery (1995). Echinococcus and hydatid disease $1^{\text {st }}$ ed. Wallingford, CAB International. 989-997 p.

Torgerson, P.R. (2006). WHO classification of alveolar echinococcosis: principles and application. Parasitol. Int. 55: 283-287.

Zeghir-Bouteldja, R., A. Polomé, S. Bousbata, and C. Touil-Boukoffa (2017). Comparative proteome profiling of hydatid fluid from Algerian patients reveals cyst location-related variation in Echinococcus granulosus. Acta. Trop. 171:199206.

Zhang, W., J. Li, and D.P. McManus (2003). Concepts in immunology and diagnosis of hydatid disease. Clin. Microbiol. Rev. 16 (1), 18-36. 